\title{
Beryllium Wipe Sampling (differing methods - differing exposure potentials)
}

\author{
by \\ Kent Kerr \\ National Nuclear Security Administration \\ Kansas City Site Office \\ Health Programs
}

\begin{abstract}
Disclaimer: This study was sponsored by an agency of the United States Government. Neither the United States Government nor any agency thereof, nor any of their employees, makes any warranty, express or implied, or assumes any legal liability or responsibility for the accuracy, completeness, or usefulness of any information, apparatus, product or process disclosed, or represents that its use would not infringe privately owned rights. Reference herein to any specific commercial product, process or service by trade name, trademark, manufacturer, or otherwise does not necessarily constitute or imply its endorsement, recommendation, or favoring by the United States Government or any agency thereof. The views and opinions of authors expressed herein do not necessarily state or reflect those of the United States Government or any agency thereof.
\end{abstract}

\section{Introduction}

Beryllium was identified in its oxide form in 1798, named "Glucinium," reduced to metallic form in 1828 , renamed beryllium (Be), and began being commercially used as a hardening and toughening agent in metal alloys in 1918. Additional uses have continued to emerge. Today Be is a key ingredient in aerospace products, weapons, electronics, nuclear reactors, sports equipment and automobile accessories, springs, non-sparking tools, molds for resin injection, dental applications, golf clubs, fiber optic equipment, cellular network communication systems, bicycle frames, wheels, and precision instruments. ${ }^{(1)}$

\section{Beryllium Health Effects and Exposure Limitations}

Evidence of negative health effects associated with Be began emerging from Europe during the 1930s but was ignored in the United States (U.S.). In the U.S., medical literature began documenting chemical pneumonia associated with occupational exposures to beryllium oxide in $1943,{ }^{(2)}$ but controversy regarding health effects was perpetuated by faulty research reporting by the U.S. Public Health Service. ${ }^{(3)}$ Between 1947 and 1949, Be was confirmed to be the active agent associated with lung disease in Be factory workers.

In 1949 the Atomic Energy Commission (AEC), a major governmental user of Be, proposed that occupational exposures to airborne Be dust be limited to $2 \mu \mathrm{g} / \mathrm{m}^{3}$ with a maximum limit of 25 $\mu \mathrm{g} / \mathrm{m}^{3}$, and a monthly average of $0.01 \mu \mathrm{g} / \mathrm{m}^{3}$ in neighborhood air around Be processing plants. ${ }^{(4,5)}$ That limit was later adopted by the EPA as the National Emission Standard for Beryllium, which is still the clean air standard for ambient air in the vicinity of Be processing facilities. ${ }^{(6)}$ The recommended $2 \mu \mathrm{g} / \mathrm{m}^{3}$ limit for air inside Be processing facilities was specified in federal government contracts with Brush and was later adopted as a Threshold Limit Value by the American Conference of Governmental Industrial Hygienists (ACGIH) in 1957. ${ }^{(4,7)}$ In addition to being extremely toxic and the cause of Chronic Beryllium Disease (CBD), Be has been determined to be a known human carcinogen with inhalation being the principle route of exposure. ${ }^{(8,9,10,11,12,13)}$

\section{Beryllium Disease Prevention and Wipe Sampling}

The Department of Energy (DOE), successor agency of the AEC, has remained committed to studying the health effects of Be and finding effective methods of protecting workers, their families, and the public from Be contamination. Pursuant to those obligations, the DOE promulgated 10 CFR 850 "Chronic Beryllium Disease Prevention Program," (CBDPP) which became effective January $7,2000 .{ }^{14}$ 
The CBDPP specified not-to-exceed removable surface contamination levels, but did not specify a standard sampling method. ${ }^{(15)}$ This has resulted in inconsistent sampling results and, subsequently, differing amounts of Be contamination remaining on equipment and facility surfaces. A recent survey indicated that of eighteen DOE installations, eleven used watermoistened wipe sampling materials, six facilities wipe-sampled with dry materials, and one used alcohol-moistened wipe materials. ${ }^{(16)}$

The CBDPP requires that Be work area surfaces be cleaned to assure no more than $3 \mu \mathrm{g} \mathrm{Be} / 100$ $\mathrm{cm}^{2}$ removable contamination. If the work area or equipment will be released for other uses, surfaces must be cleaned so that removable contamination does not exceed $0.2 \mu \mathrm{g} \mathrm{Be} / 100 \mathrm{~cm}^{2}$. These cleanliness criteria were considered achievable based on prior experience at various DOE facilities. However, the wipe sampling methods being used at those facilities were not specified.

The removableness of surface contamination in metal machining shops is affected by oil mist residues generated when metal working fluids (MWF) are used to cool and lubricate the metal abrading/cutting processes. Oil mist aerosols generated in such metal machining shops leave somewhat tacky surface residues on walls, ceilings, shelving, and equipment that respond significantly differently to dry paper wipes than to water-moistened wipes or alcohol-moistened wipes. If a less-than-adequate method of wipe sampling is employed, erroneous decisions may be made regarding decontamination and facilities or equipment could be released with surface contamination significantly more than $0.2 \mu \mathrm{g} \mathrm{Be} / 100 \mathrm{~cm}^{2}$.

The surface sampling provisions of the CBDPP were explicitly intended to verify minimization of respiratory exposure to Be particulates. ${ }^{(17)}$ However, since the implementation of the CBDPP in 2000 , an increasing body of evidence has developed implicating skin contact with Be sensitization. ${ }^{(18,19,20,21)}$ Since sensitization is an integral step in the development of CBD, this raises additional issues regarding the importance of removing Be contamination from surfaces. Using dry paper or water-dampened wipes can prejudice sampling results by avoiding the collection of lipid-laced contamination residues in shops with historical use of MWF.

\section{Purpose}

The purpose of this study was to determine if there was a consistent significant relative difference in the removal efficiency of alternate wipe sampling methods being used within the DOE complex. Specifically, this research sought to establish the removal efficiency of wipe sampling with dry Whatman smear tab paper, versus wipe sampling with Ghost Wipes (water-moistened wipes), versus wipe sampling with methanol-moistened gauze wipes on a surface texture and residue typical of metal-machining shops. It was hypothesized that methanol-moistened wipe sampling would remove a greater percentage of Be surface contamination associated with metal-working fluid residue from a typical painted surface than dry or water-moistened wipe sampling.

\section{Method}

Test plates were prepared using $100 \mathrm{~mm} \times 15 \mathrm{~mm}$ Pyrex Petri dishes having interior surfaces spray painted with a bond coat primer. To achieve uniform deposition over the test plate surface, precisely-measured aliquots of solution with known Be mass were transferred by pipette to the test plates and subsequently evaporated. A small amount of a semi-synthetic metal working fluid was added to the Be solution used to "contaminate" the test plates. Sixteen test plates were processed and wipe sampled for each wipe method (dry, water-, and methanol-moistened).

The residue applied to the painted surface of the test plates was formulated to contain $1 \mu \mathrm{g} \pm$ $0.002 \mu \mathrm{g} \mathrm{Be}$ and $0.1 \mathrm{ml}$ of a metal working fluid concentrate per $78.54 \mathrm{~cm}^{2}$ (the equivalent of 1.25 $\mu \mathrm{g} \mathrm{Be}$ and $0.13 \mathrm{ml}$ of a metal working fluid per $100 \mathrm{~cm}^{2}$ ). The oily film resulting from fugitive MWF mist typically oxidizes after extended periods to produce a slight tackiness on shop surfaces. Test plates were baked at $230^{\circ} \mathrm{F}$ for 25 minutes to simulate the aging effect. Control and field blanks were collected to control for possible sources of contamination inherent in the 
preparation, and sampling. All test and control plates were wiped with uniformly consistent patterns (see Figure 2) using the three wipe materials typically used at DOE facilities.

The first set of test plates to be sampled was the series wiped with dry Whatman paper. A portion of the slightly reddish-brown color of surface contamination, caused by the colored MWF, transferred onto paper when it was firmly pressed and wiped over the test plate surface. Use of the same pressure with the Ghost Wipes for the next series of plates squeezed water out of the folded wipes. Water was sopped up to avoid loss of removal efficiency and wiping pressure was moderated with the remaining moistened wipes. There was no significant visible difference between the removal accomplished by water-moistened and alcohol-moistened wipes. All used wipe materials were placed in lab vials, sealed, marked with date and time and transferred to the analytical lab with a chain of custody document. The wipe samples were analyzed using EPA method 6010B "Inductively Coupled Plasma - Atomic Emission Spectrometry (ICP-AES)." Analytical results were used to calculate comparative removal efficiencies, the variances of which were analyzed for statistically significant difference using one-way analyses of variance (ANOVA) and Multiple-Fs post hoc testing.

\section{Results}

The mean removal efficiency rates ( $n=15$ for each method) were as follow:

- $\quad$ Dry wipes: $9.33 \%($ S.D. $=2.80)$,

- Water-moistened wipes: $22.97 \%($ S.D. $=6.05)$,

- Alcohol-moistened wipes: $50.62 \%$ (S.D.= 9.54),

as shown on the histogram of Figure 1.

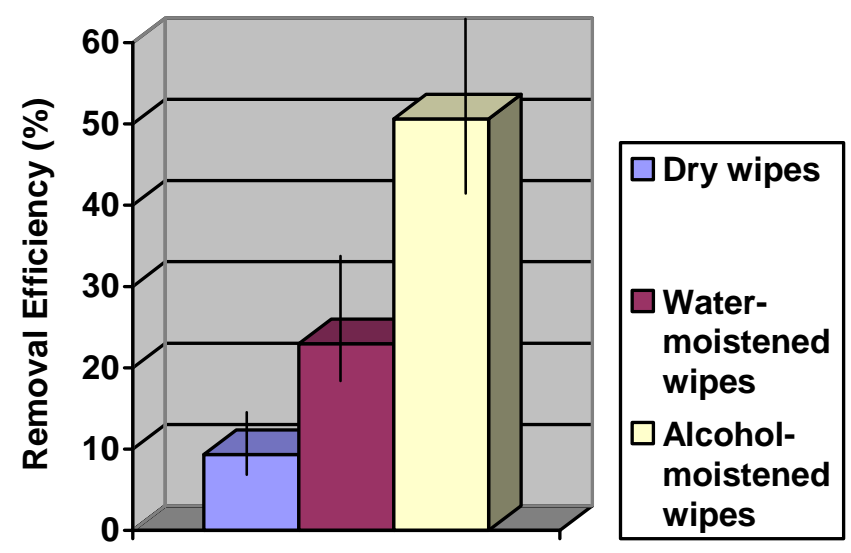

Wipe Method

Figure 1. Mean Removal Efficiencies (\%)

Removal efficiencies for dry, water-moistened, and alcohol-moistened wipe sampling were also plotted as a frequency distribution bar chart. Values along the $x$-axis are removal efficiency range intervals and the heights of the bars reflect the numbers of sample per range, see Figure 2. This visual aid illustrates the relatively tighter distribution (less variance) of removal efficiencies experienced with dry wipe sampling. This may be partially attributable to the fact that while moistened sampling techniques removed more of the surface contamination, they also left behind varying amounts of liquid. It would appear reasonable that the greater the solvent effect of the wetting agent, the more contaminant would be contained in the moisture left behind. Imperfect 
control of wiping pressures and differing moisture content could account for variable quantities of liquid left behind and hence more diverse removal efficiencies for moistened wipe materials.
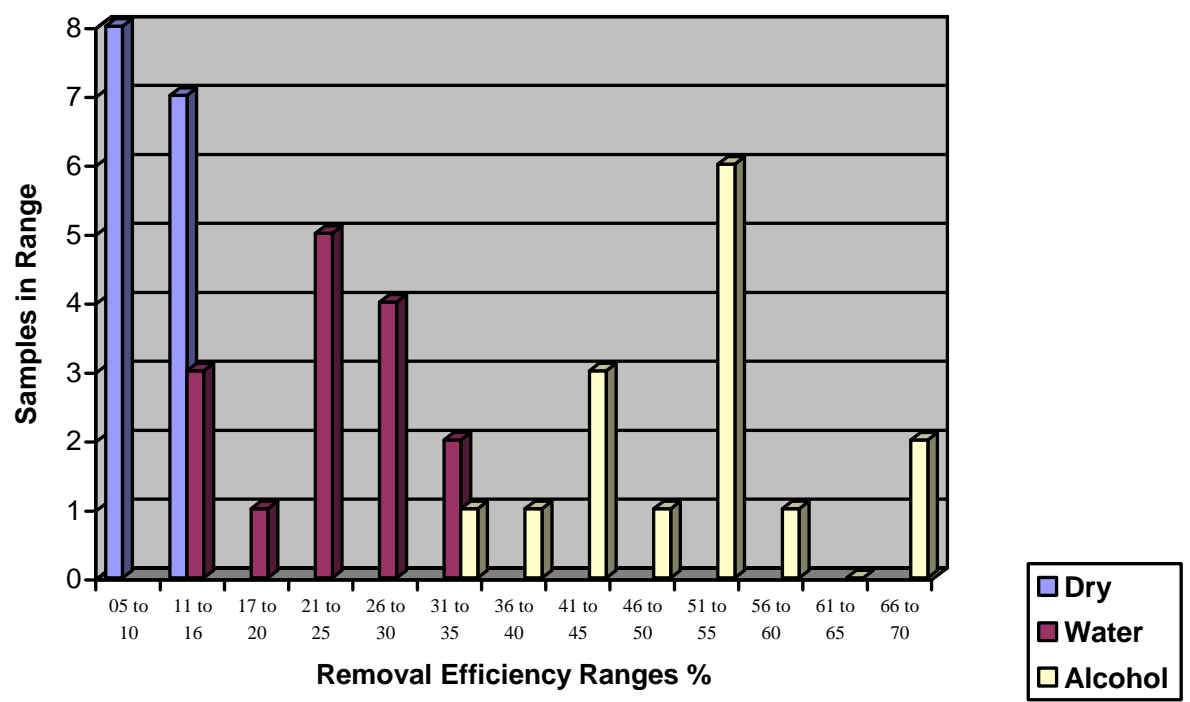

Figure 2. Frequency Distribution of Removal Efficiencies

Sampling results analyzed with single factor Analysis of Variance (ANOVA) showed that there were significant differences in the removal efficiencies of the three wipe sampling methods being compared [F=146.87 (2,42), $\mathrm{P}=1.1 \mathrm{E}-19$, SIG]. Post Hoc Multiple- $\mathrm{F}$ analysis of the test results demonstrated that, as predicted, water-moistened wipe sampling had significantly greater removal efficiency than dry wipe sampling, and alcohol-moistened wipe sampling had significantly greater removal efficiency than water-moistened wipe sampling $(p<0.01)$.

\section{Discussion and Conclusions}

This study was founded on the proposition that management can ill afford to ignore such excellent evidence as that provided by the research of Tinkle et al., ${ }^{(18)}$ and the dramatic drop in sensitization experienced by Brush Wellman following implementation of skin protection policies. ${ }^{(20,21)}$ Those responsible for decontamination of facilities and equipment in the interest of human health must give serious consideration to the possibility of skin-mediated Be-sensitization. Due to environmental sources, sensitized individuals are at greater risk of developing CBD even if not occupationally exposed to Be. The choice of wipe sample wetting agents has increased importance in light of findings that skin contact plays a valid role in Be disease conditions.

The issue of leaving behind Be in moisture remaining on surfaces sampled with moistened wipe materials could be resolved by adding a step to dry the surfaces with ashless filter paper to be included in the sample vials for digestion along with the moistened wipe materials. This modified sampling procedure would provide more consistent and accurate information regarding levels of surface contamination when making decisions regarding the need for decontamination.

Methanol-moistened wipe sampling identified twice as much machine shop Be surface contamination as compared to water-moistened wipe sampling and about five times as much as dry wipe sampling. Whereas there is no certainty that the remaining not-so-removable surface 
contamination poses any real threat to unprotected users, there would probably be no ethicallysupportable rationale for using less effective sampling methods.

The fact that the CBDPP cleanliness criteria were based on results from uncharacterized surface residues and unspecified wipe sampling methods raises questions about comparability and feasibility. Considering the results of this study, it could be five times more difficult to achieve the CBDPP cleanliness criteria with alcohol-moistened wipe sampling than with dry wipe sampling. The method(s), surfaces, and nature of residues used to establish the criteria given at 10 CFR 850.30 and .31 significantly influenced the values of those criteria. Good faith efforts to comply with those criteria must use the same method(s) to remove similar residues from similar surfaces, or derive equivalency factors via valid controlled comparison studies.

In the case of surfaces contaminated with Be, together with fugitive oil mist residues typical for metal working shops, this study indicates that methanol is a better wetting agent than water. Selection of inappropriate wetting agents can potentially jeopardize the health of current $\mathrm{Be}$ workers, as well as users of facilities or equipment released according to the provisions of CBDPP regulations.

\section{Recommendations}

Selection of water-moistened or alcohol-moistened wipe materials should be based on the historical use of the facility/equipment and the observed nature of the surface contamination. If deposits are dry and dusty, water-moistened wipes would be appropriate, whereas methanol wipes would be more appropriate if an oil film is present. Evidence for Be sensitization via skin exposure argues in favor of wipe sampling with wetting agents that provide greater residue removal efficiency.

The Department of Energy should identify the method(s), surfaces, and nature of residues used to establish the criteria given at 10 CFR 850.30 and .31 and allow for equivalency factors based on valid local-condition comparison studies. 


\section{References}

${ }^{1}$ Newman, L.S., (2003). Beryllium. Chemical \& Engineering News, Vol. 81, Issue 36, p. 38.

${ }^{2}$ Van Ordstrand, H.S. Hughes, R., \& Carmody, M.G. (1943). Chemical pneumonia in workers extracting beryllium oxide. Report of three cases. Cleve Clin Quart, 10:10, as cited in Tepper, L.B., (1991). Introduction. In Rossman, M.D., Preuss, O.P., Powers, M.B. (Ed.), Beryllium - Biomedical and Environmental Aspects (pp. 59-75). Baltimore: Williams \& Wilkins.

${ }^{3}$ Hyslop, R., Palmes, E.D., Alford, W.C., Monaco, A.R., Fairhall, L.T. (1943). Toxicology of beryllium. Nat Inst Health Bull. No. 181. Cited in Reeves, A.L. (1991). Experimental pathology. In Rossman, M.D., Preuss, O.P., Powers, M.B. (Ed.), Beryllium - Biomedical and Environmental Aspects (pp. 59-75). Baltimore: Williams \& Wilkins.

${ }^{4}$ Brush Wellman (2003). Beryllium facts. Retrieved 11/03/2003 from: http://www.befacts.com/timeline

${ }^{5}$ Eisenbud, M. (1982). Origin of the standards for control of beryllium disease (1947-1949). Environ Res, Vol. 27, pp. 79-88. As referenced in Powers, M.B. (1991). History of beryllium. In Rossman, M.D., Preuss, O.P., Powers, M.B. (Ed.), Beryllium Biomedical and Environmental Aspects (pp. 59-75). Baltimore: Williams \& Wilkins.

${ }^{6}$ EPA (2003ii). Code of Federal Regulations, Title 40, Protection of Environment, Part 61, National Emission Standards for Hazardous Air Pollutants, Subpart C, National Emission Standard for Beryllium, Sec. 61.32. Retrieved 11/21/2003 from: http://frwebgate3.access.gpo.gov/cgibin/waisgate.cgi?WAISdocID=4405078579+2+2+0\&WAISaction=re

${ }^{7}$ ACGIH (2003). Two thousand three TLVS and BEIs, threshold limit values for chemical substances and physical agents \& biological exposure indices, Cincinnati, Ohio, ACGIH.

${ }^{8}$ NTP (2002). Report on Carcinogens, Tenth Edition, U.S. Department of Health and Human Services, Public Health Service, National Toxicology Program, as retrieved 11/03/2003 from http://ehp.niehs.nih.gov/roc/tenth/profiles/s022bery.pdf

${ }^{9}$ IARC (1997). Beryllium and beryllium compounds - Group 1. International Agency for Research on Cancer (IARC) monograph, retrieved 11/03/2003 from: http://193.51.164.11/htdocs/monographs/vol58/mono58-1.htm

${ }^{10}$ Goyer, R.A., \& Clarkson, T.W. (2001). Toxic effects of metals. In Klaassen, C.D. (Ed.) Casarett \& Doull's Toxicology, The Basic Science of Poisons, New York: McGrawHill, pp.811-867.

${ }^{11}$ RTECS (2002). Beryllium. NIOSH document retrieved 11/17/2003 from: http://www.cdc.gov/niosh/rtecs/ds1ab3fo.html

12 OSHA (1994). 29 CFR 1910.1000 Table Z2 Toxic and Hazardous Substances. Retrieved 11/17/2003 from: http://osha.gov/pls/oshaweb/owadisp.show document?p table=STANDARDS\&p id=999 $\underline{3}$

${ }^{13}$ Public Health Service. (2002). Toxicological Profile for Beryllium. U.S. Department of Health and Human Services, Public Health Service Agency for Toxic Substances and Disease Registry. Retrieved 10/21/04 from: www.atsdr.cdc.gov/toxprofiles/tp4.pdf

${ }^{14}$ DOE (1999). Chronic beryllium disease prevention program. 10 CFR Part 850 [Docket No. EH-RM-98-BRYLM] RIN 1901-AA75. Office of Environment, Safety, and Health, Department of Energy. Final Rule. Federal Register, Vol. 64, No. 235, Wednesday, December 8, 1999, Rules and Regulations, pp. 69954-68914. Retrieved 9/1/04 from: http://www.eh.doe.gov/bel

${ }^{15}$ DOE (1999ii). Chronic beryllium disease prevention program. 10 CFR Part 850 [Docket No. EH-RM-98-BRYLM] RIN 1901-AA75. Office of Environment, Safety, and Health, Department of Energy. Final Rule. Federal Register, Vol. 64, No. 235, Wednesday, December 8, 1999, Rules and Regulations, portion of Preamble discussing Section 850.30 , p. 68885, column 2, ๆ 4. 
${ }^{16}$ BHSC (2004). Beryllium Health and Safety Committee meeting at Desert Research Institute, Las Vegas, Nevada. October 19, 2004 meeting minutes. Retrieved 11/05/04 from: http://www.sandia.gov/BHSC/events/MinutesOCT2004.pdf

${ }^{17}$ DOE (1999i). Chronic beryllium disease prevention program. 10 CFR Part 850 [Docket No. EH-RM-98-BRYLM] RIN 1901-AA75. Office of Environment, Safety, and Health, Department of Energy. Final Rule. Federal Register, Vol. 64, No. 235, Wednesday, December 8, 1999, Rules and Regulations, portion of Preamble discussing Section 850.30, p. 68884, column 3, ๆ 2.

${ }^{18}$ Tinkle, S.S., Antonini, J.M., Rich, B.A., Roberts, J.R., Salmen, R., DePree, K., \& Adkins, E.J. (2003). Skin as a route of exposure and sensitization in chronic beryllium disease. Environmental Health Perspectives, 111, 1202-1208.

${ }^{19}$ Munson, A., \& Luster, M. (2003). Dermal exposure leading to respiratory tract sensitization and disease: a trivial or critical link? Toxicologist, Vol. 72(S-1), p.60. Retrieved 11/14/2003 from: http://www2a.cdc.gov/nioshtic2/BuildQyr.asp?s1=beryllium\&f1=\%2A\&Startyear=\&Adv=0\&terms $=1 \&$ EndYear $=\&$ Limt $=10$ $000 \&$ sort $=\& D 1=10 \& P a g e N o=1 \& R e c N o=3 \& V i e w=e \&$

${ }^{20}$ McCawley, M. (2002). "What have we learned about protecting workers from beryllium." Mike McCawley, sharing lessons learned at Brush Wellman, made this presentation at the Kansas City Plant Beryllium Forum on 7/25/02. McCawley Consulting Morgantown, WV (tel. 304-685-4470). The video file was reviewed 10/30/04 from the KCP in-plant television network x.iptv-file:0 nameES\&HVideos/Be_Mcawley.mpg.

${ }^{21}$ Brush Wellman (2002). Comprehensive exposure pathway control program. Poster presented at the 2002 AlHA Conference. Retrieved 10/30/04 from: http://www.brushwellman.com/ehs/ohr/2002aihaposterfinal.pdf 